\title{
Exploring the Construction of Open Laboratory for Automobile Engineering Based on Excellent Engineer Plan
}

\author{
Hao Luo \\ School of Mechanical and Electrical Engineering and Automotive Services, Wuhan Business \\ University, Wuhan, Hubei, 430056, China
}

Keywords: Excellent engineer plan, open laboratory, experimental topic selection.

\begin{abstract}
Excellent engineers plan" is to place emphasis on closer cooperation between higher engineering education and industry. The open laboratory of colleges and universities plays a bridge role between universities and enterprises in the plan. In view of the problems faced by the open laboratory, such as the complex scheduling of experimental resources, the structural contradiction of teacher allocation and the low level of scientific and technological innovation experiment content, this paper discusses the construction of intensive management open laboratory, the selection of experimental topics and the opening mechanism of laboratory. Practice shows that the exploration is effective in improving laboratory opening level and innovation level.
\end{abstract}

\section{Introduction}

In June 2010, the Ministry of Education launched the Education and Training Program for Excellent Engineers (hereinafter referred to as the "Excellence Program"), which aims to train many high-quality engineering and technical personnel with strong innovative ability to meet the needs of economic and social development, and to take the road of new industrialization for the country. Set up an innovative country and talent power strategy service. The "Excellence Plan" is characterized by the creation of a new mechanism for the joint training of talents between universities and industry enterprises, and the strengthening of engineering and innovation capabilities of College students. Open laboratory is partly or completely open in time, space, content, method and means. It is a bridge between universities and enterprises and an effective way to promote students 'innovative ability ${ }^{[1]}$.

Zhengzhou Institute of Light Industry set up an open laboratory in 2001, which is open to mechanical and near mechanical students. Over the past 10 years, the laboratory has achieved good results in the "Challenge Cup" National College Students 'Extracurricular Academic and Technological Works Competition, National College Students' Machinery Innovation Design Competition, and College Students 'Engineering Training Competition. But in the process of open laboratory construction, there are some challenges, such as extensive open mode, low efficiency of software and hardware resources utilization, blindness and breadth of experimental topics, insufficient depth of research, lack of sustainability, rigid open mechanism, inadequate vitality of 
learning and research. In view of these problems, we have been exploring in practice and achieved good results ${ }^{[2]}$.

\section{Construction of intensive open laboratory}

\subsection{Extensive features of traditional open laboratories}

The construction of open laboratory has changed the focus of traditional laboratory work, that is, from verifying, consolidating and deepening the content of theoretical teaching to training students 'practical ability, innovative ability and problem-solving ability. Laboratory opening is conducive to the full use of laboratory equipment resources, can mobilize students 'learning enthusiasm and subjective initiative, more in line with the requirements of quality education training objectives. However, in the process of building an open laboratory, there are also some shortcomings of a more extensive open model, which are embodied in the following two aspects: the use and management of hardware and software resources ${ }^{[3]}$.

The extensive use and management of hardware resources are embodied in the management of experimental instruments and equipment, and there are often repeated construction and excessive investment. Lack of overall design in laboratory opening, the main contradiction is the independence of teaching units and the integration of open laboratory experimental projects. Experiments in open laboratories for mechanical design majors are often the same or similar as those in open laboratories for mechanical manufacturing majors. The same equipment and the same experimental instrument are purchased repeatedly. Another prominent problem is overinvestment and one-sided pursuit of the advanced nature and comprehensiveness of equipment. For example, the comprehensive performance test-bed of mechanical efficiency, which originally required students to measure their own data, collate data, analysis data, but some of the equipment ordered to completely ignore these necessary content and steps, directly give the efficiency curve of the measured mechanism, so the training of students 'practical ability and analysis ability is very limited.

The use and management of software resources are mainly due to the waste of experimental project resources and the disorder of experimental instructor resource management. Experiments carried out in open laboratories are often directly related to teachers 'scientific research. Technical reports and related documents of projects directly related to experimental contents are valuable assets of laboratories. However, a significant feature of scientific research projects is the time limit. If these data can not be well managed, experiments will inevitably result. Waste of resources is not conducive to the sustainable development of laboratories. Another prominent problem in the use and management of open laboratory software resources is the disorderly management of experimental instructor resources. Most university teachers are assigned to various research institutes or centres, and laboratory managers are often assigned to guide open experimental projects according to their own understanding of the faculty. Whether the tutor is suitable or not depends largely on the familiarity of the laboratory managers with the tutor's research projects. In many cases, they can not understand the scientific research projects of each teacher so deeply. This will inevitably lead to the experimental projects can not find the appropriate tutor, and tutors. Teacher's experimental project is not the best subject.

\subsection{Intensive and meticulous opening laboratory construction}

To overcome the above typical problems caused by extensive management in open laboratory construction, our idea is to build intensive and fine open laboratory, including intensive and fine management of hardware resources and intensive and fine management of software resources. 
Hardware resources management is mainly the acquisition, use, scrap of experimental equipment life cycle management mode. In the purchase of laboratory equipment, the secondary demonstration system is mainly implemented in the whole hospital, breaking the limitation of the division of departments, research institutes and centres. Every school year, the basic units of teaching and scientific research put forward the equipment purchase plan and demonstration report of open laboratory. According to the function division of open laboratory, the college integrates the equipment purchase plan. The main idea is to optimize the equipment with the same function or similar configuration in a laboratory ${ }^{[4]}$. When choosing the experimental equipment, the basic guiding ideology is to be able to answer what the equipment can do at present, what can be done in the future, the equipment to students 'hands-on ability, problem analysis ability, innovation ability training embodied in where. Open laboratory projects can be organized and implemented according to the division of labour and cooperation of several laboratories. In the process of using the equipment, we formulate the system of using the equipment, for example, for the mechanical creative combination of experimental equipment, we design the equipment management table as shown in Table 1, at any time we can find problems in the use of the equipment. The scrap of equipment should also be strictly demonstrated, and several results such as continuous use, transformation and scrap should be given to improve the utilization rate of equipment and reduce waste.

Table 1 Creative combination model component inventory

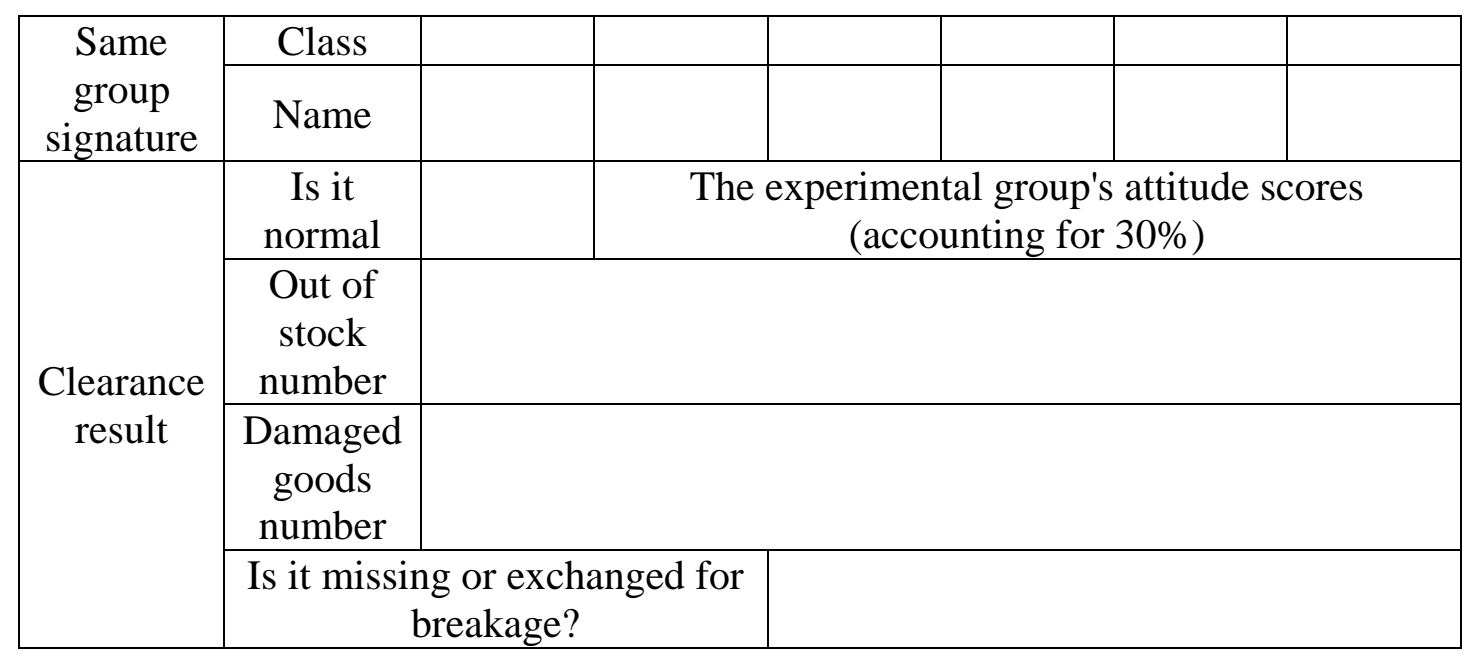

The construction of laboratory software resources is also very important, of which the more important is the project management of open laboratory and the management of experimental instructor resources. Scientific and technological project resources are the precious wealth of the laboratory, if not well managed and applied will be a huge waste of laboratory sustainable development is also unfavorable. According to the type of the project, the data are classified and stored, and the resource bank of the construction project is constructed. Collate data regularly and update the contents of the repository and pay attention to the technological evolution of the project. Make resource database publicity materials, so that we can understand the contents of the repository. At the same time, the resource pool is open to teachers and students in the whole school to achieve knowledge sharing. For the same type of open experiment project, learn from the existing information, on the one hand, we can learn from the experience, on the other hand, we can update the development context of related technology. Experimental instructor resources are another valuable resource for opening laboratories. Because of the characteristics of open experiment, the requirement for experimental instructors is relatively high. For an open experiment project, how to find a suitable instructor is a common problem. We should set up a resource pool for teachers and 
integrate teachers' data scattered in different departments and institutes. The interaction between teachers, students, laboratory administrators and teacher resources are shown in Figure 1. According to the content of the experimental project, the person in charge of the experimental subject can organize one or more teachers to guide in the teacher resource bank ${ }^{[5]}$.

\section{Open laboratory experiment topic selection mechanism construction}

The topic selection of open laboratory experiment projects is generally comprehensive, innovative, and closely integrated with teachers 'scientific research activities. Combining with the training goal of "Excellence Plan", we should also consider the cultivation of students 'interest, the content of project selection and the orientation of project selection.

First, the subject selection of experimental projects should be carried out in combination with students' scientific research interest and teachers' scientific guidance. After studying the basic knowledge of the University curriculum, many students are eager to try, hoping to be able to apply the knowledge learned to practical topics, at the same time, they will also have great confusion, do not know how to combine the knowledge of books with the specific application. At this time, teachers are required to conduct proper guidance. Figure 2 shows the student's work "sprinkler robot", which is an open experimental project after learning the basic courses of mechanical principles, mechanical control foundation, hydraulic and pneumatic. This work is composed of mechanical part, pneumatic part and control part. It realizes remote control robot to sprinkle water through the network.

Secondly, the content of experimental project should reflect the combination of knowledge coverage and breakthrough of knowledge points. As an open experimental project, its comprehensive manifestation is to cover as much knowledge as possible, through an experimental project to train students to apply and master multiple related knowledge. However, a good experimental project should also reflect the advanced nature. Therefore, the topic selection is not only reflected in the simple accumulation of knowledge points, but also should have a breakthrough at some point or a certain point. As shown in Figure 3, the student's experimental project "Centrally Driven Cam-Link Combination Mechanism", which includes the geometric model of cam mechanism, linkage mechanism and their combination, the kinematic model of mechanism simulation and the knowledge of kinematic cycle diagram of mechanical system, as well as computer graphics and calculation, is trained. Ability of machine programming. The breakthrough of the students in the experiment is to draw the movement cycle diagram of the mechanism correctly according to the requirements of the movement law of the mechanism, and to carry out the computer aided geometric design of the combined mechanism.

In addition, the direction of the research project should be combined with the direction of national science and technology development. "Excellence Plan" aims to train many innovative abilities, meet the needs of economic and social development of high-quality engineering and technical personnel, for the country to take the road of new industrialization, the construction of an innovative country and the strategic service of talent power. The organization and implementation of open experimental projects should implement the training objective of the "Plan of Excellence", and the selection of experimental topics should be consciously combined with the development direction of science and technology of the country. In addition, students are encouraged to take an active part in the extracurricular academic and technological competitions ("Challenge Cup"), the undergraduate innovation and entrepreneurship training program and the national undergraduate discipline competitions sponsored by the Ministry of Education, such as the undergraduate mechanical design competition, structural design competition, engineering training competitions, etc. According to the schedules of various competitions, the College has mobilized students from 
various channels, namely, the College-Counselor-Class Cadre-Student System, the College-Course Teacher-Student System, and the Laboratory-Website-Student System. The College has carried out laboratory demonstration on the experimental project of the Student Newspaper to grasp the advanced nature of the project. And feasibility. Figure 4 is part of the entries for students in the open laboratory.

\section{Conclusion}

At present, the relevant research on counterpart support to western universities is still mainly focused on the overall policy and system of counterpart support work, but lacking of the systematic research results on the model and countermeasures of counterpart support laboratory construction. In the future, we should further strengthen the research and thinking about this aspect and form an effective description of the aid construction, and finaly put forward more targeted and guiding suggestions to better enhance the level of counterpart support work.

\section{References}

[1] Zhang Li. Research on the Collaborative Mechanism of Project-based Management for Training Excellent Engineers [D]. North China Electric Power University (Beijing), 2017.

[2] Xu Chonghai, Fang Bin, Zhang Peng, Qiu Shubo, Shi Yanbin, Xiao Guangchun and Zhang Jingjie. The training mode of Engineering application-oriented talents for mechanical specialty accredited by outstanding engineers and engineering education [J]. Journal of Higher Education, 2015 (21): 52-54.

[3] Du Wenliao, Li Ansheng, Wang Liangwen, Wang Xinjie. Exploration of Open Laboratory Construction for the Excellent Engineer Program [J]. Laboratory Technology and Management, 2014, 31 (11): 218-221+225.

[4] NGUYEN MINH QUAN (Ruan Mingjun). A comparative study on the education of outstanding engineers between China and Vietnam [D]. Kunming University of Technology, 2014.

[5] Lin Jian. The cultivation of outstanding engineers' innovative ability [J]. higher engineering education research, 2012 (05): 1-17. 